\title{
Europium coordination compounds based on carbacylamidophosphate ligands for metal-organic light-emitting diodes (MOLEDs)
}

\author{
O.O. Litsis ${ }^{1}$, V.A. Ovchynnikov ${ }^{1}$, T.Yu. Sliva ${ }^{1}$, V.M. Amirkhanov ${ }^{1}$, V.M. Sorokin ${ }^{2}$, M.A. Minyailo ${ }^{2}$, \\ Yu.V. Kolomzarov ${ }^{2}$, P.A. Tytarenko ${ }^{2}$, I.E. Minakova ${ }^{2}$ \\ ${ }^{I}$ Taras Shevchenko Kyiv National University, Department of Chemistry \\ 64/13, Volodymyrska Str., 01601 Kyiv, Ukraine \\ Phone: 38(044)239-33-92; e-mail: allicis@yahoo.com \\ ${ }^{2} V$. Lashkaryov Institute of Semiconductor Physics, NAS of Ukraine \\ 41, prospect Nauky, 03028 Kyiv, Ukraine \\ Phone: 38(044)525-31-26; e-mail: kolomzarov@isp.kiev.ua
}

\begin{abstract}
In this work, the photo- and electroluminescence properties of new red phosphores based on europium complexes with carbacylamidophosphate (CAPh) ligands and additional aromatic ligands 1,10-phenantroline and 4,4'-bipyridine have been studied. Compounds $\mathrm{Eu}\left(\mathrm{L}^{1}\right)_{3}(\mathrm{phen})(\mathbf{1}), \mathrm{Eu}\left(\mathrm{L}^{2}\right)_{3}(\mathrm{phen})(\mathbf{2}), \mathrm{Eu}_{2}\left(\mathrm{~L}^{1}\right)_{6}(i \text {-prOH})_{2}\left(4,4^{\prime}-\right.$ bipy $)$ (3) and $\mathrm{Eu}_{2}\left(\mathrm{~L}^{2}\right)_{6}\left(\mathrm{H}_{2} \mathrm{O}\right)_{2}\left(4,4\right.$ '-bipy) (4), where $\mathrm{HL}^{1}$ - 2,2,2-trichloro-N-(dipiperidin-1-ylphosphoryl)acetamide, $\quad \mathrm{HL}^{2} \quad-\quad$ 2,2,2-trichloro-N-(dimorpholin-1-ylphosphoryl)acetamide, were synthesized. Technology of europium complexes coating from solutions with different concentrations in different solvents has been developed. Experimental samples of light-emitting planar heterostructures were fabricated using the device architecture comprising an anode (ITO), a hole transport layer of 1,4Bis(diphenylamino)benzene (BDB), a layer of complex and a cathode (Al or $\mathrm{Mg}$ ). Another heterostructure configuration with a hole-transport layer of poly $(3,4-$ ethylenedioxythiophene) poly(styrenesulfonate) (PEDOT:PSS) has also been investigated. The different types of planar heterostructures were prepared, and their current-voltage characteristics have been discussed.
\end{abstract}

Keywords: red photoluminescence, electroluminescence, europium complex, carbacylamidophosphate, metal-organic electroluminescent device, light-emitting planar heterostructure, current-voltage characteristic.

Manuscript received 26.12.12; revised version received 05.02.13; accepted for publication 19.03.13; published online 25.06.13.

\section{Introduction}

Organic electroluminescent devices (OELDs) based on organic thin layers are one of the most promising next generation flat-panel full-color display and lighting systems. Since the pioneering work by Tang and Van Slyke [1] on organic electroluminescent (EL) devices with double layers and the original report on polymer electroluminescence from a precursor-route $\operatorname{poly}(p$ phenylenevinylene) (prec-PPV) by Burroughes et al. [2], the field of organic EL has rapidly pronounced itself as a new branch of applied science. A variety of organic materials, including fluorescent dyes $[3,4]$, metal complexes [5-7], and polymers [8-11] have been reported to show electroluminescence, and various emission colors have been obtained. However, these OELDs using organic materials and polymers as the emissive layers generally produce emission due to their $\pi-\pi^{*}$ transition, whose luminescence spectra typically have a large full width at half maximum (50-200 nm) and are not well suited for actual multicolor display applications. 
Besides, these metal-organic molecules - another type of promising compounds and rare earth complexes - are anticipated to exhibit narrow emission spectra along with high efficiency. The rare earth ions exhibiting sharp spectral bands corresponding to $f-f$ electron transitions $\left(\sim 585 \mathrm{~nm}\right.$ for ${ }^{5} \mathrm{D}_{0} \rightarrow{ }^{7} \mathrm{~F}_{1}$ and $\sim 615 \mathrm{~nm}$ for $\left.{ }^{5} \mathrm{D}_{0} \rightarrow{ }^{7} \mathrm{~F}_{2}\right)$ are nearly monochromatic [12]. In the past decades, many rare earth complexes, especially those containing terbium and europium, have been used in MOELDs (metalorganic electroluminescent devices) as the emissive materials [13-16]. Most of the work is focused on rare earth $\beta$-diketonate complexes because of their good solubility and/or good volatility. Among those, the terbium $\beta$-diketonate complex $\mathrm{Tb}(\mathrm{acac})_{3}$ was first introduced into MOELDs by Kido et al. [17] and later $\mathrm{Tb}(\mathrm{acac})_{3}$ Phen was used as an emissive center, and the performance of the OELDs was improved [18].

This work is concentrated on the investigation of the photoluminescence (PL) and electroluminescence (EL) properties of the europium complexes with carbacylamidophosphate (CAPh) ligands: 2,2,2trichloro-N-(dipiperidin-1-yl-phosphoryl)acetamide

$\left(\mathrm{HL}^{1}\right)$ and 2,2,2-trichloro-N-(dimorpholin-1-ylphosphoryl)acetamide $\left(\mathrm{HL}^{2}\right)[19,20]$. Aromatic N-donor ligands 1,10-phenantroline (phen) and 4,4'bipyridine (4,4'-bipy) were included into the structure, since they are able to enhance the luminescence intensity and the electron transport properties of the material [21]. We have synthesized four CAPh containing complexes, namely: $\operatorname{Eu}\left(\mathrm{L}^{1}\right)_{3}($ phen $)(\mathbf{1}), \mathrm{Eu}\left(\mathrm{L}^{2}\right)_{3}($ phen $)(2), \operatorname{Eu}_{2}\left(\mathrm{~L}^{1}\right)_{6}(i$ prOH $)_{2}\left(\gamma \gamma^{\prime}\right.$-bipy) (3) and $\mathrm{Eu}_{2}\left(\mathrm{~L}^{2}\right)_{6}\left(\mathrm{H}_{2} \mathrm{O}\right)_{2}\left(\gamma \gamma^{\prime}\right.$-bipy) (4), as well as studied their photoluminescence properties. Technology of organic and metalorganic coating layers was developed. Experimental samples of light-emitting planar heterostructures were fabricated using the device architecture comprising an anode (ITO), a hole transport layer of 1,4-Bis(diphenylamino)benzene (BDB), a layer of complex and a cathode $(\mathrm{Al})$. Another heterostructure configuration with a hole-transport layer of poly $(3,4$ ethylenedioxythiophene) poly(styrenesulfonate) (PEDOT:PSS) has been also investigated. These two types of devices were prepared, and their current-voltage characteristics have been discussed.

\section{Experimental}

\subsection{Materials}

$\mathrm{Eu}\left(\mathrm{NO}_{3}\right)_{3} \cdot 6 \mathrm{H}_{2} \mathrm{O}, 1,10$-phenanthroline monohydrate and 4,4'-bipyridile of commercial grade were used without further purification. The 2,2,2-trichloro-N-(dimorpholin1-yl-phosphoryl)-acetamide (HL) was synthesized according to the previously published procedure [19]. All other materials and solvents were of reagent grade, obtained from commercial sources and used without further purification. Indium tin oxide (ITO) coated glass substrates with the surface resistivity 8-10 Ohm per square were purchased from Sigma-Aldrich, Co, USA.

\subsection{Synthesis of the europium complexes}

The solution of $\mathrm{Eu}\left(\mathrm{NO}_{3}\right)_{3} \cdot 6 \mathrm{H}_{2} \mathrm{O}(0.4382 \mathrm{~g}, 1 \mathrm{mmol}$, previously dehydrated by $6 \mathrm{mmol}, 0.996 \mathrm{ml}$ $\left.\mathrm{HC}\left(\mathrm{OC}_{2} \mathrm{H}_{5}\right)_{3}\right)$ in acetone $(10 \mathrm{ml})$, was added to a solution containing $\mathrm{NaL}(3 \mathrm{mmol})$ and 1,10 phenanthroline $(0.1982 \mathrm{~g}, 1 \mathrm{mmol})$ (or 4,4'-bipyridine $0.1562 \mathrm{~g}, 1 \mathrm{mmol})$ in isopropanol $(10 \mathrm{ml})$. The resulting mixture was filtrated from the sodium nitrate precipitate

Table 1. Analytical data of the synthesized complexes.

\begin{tabular}{|c|c|c|c|c|c|}
\hline Complex & Yield (\%) & \multicolumn{4}{|c|}{ Found (calc.) (\%) } \\
\cline { 3 - 6 } & & $\mathrm{Eu}$ & $\mathrm{C}$ & $\mathrm{H}$ & $\mathrm{N}$ \\
\hline $\mathbf{1}$ & 81 & $10.1(10.3)$ & $3.15(2.99)$ & $5.67(5.78)$ & $0.70(0.59)$ \\
\hline $\mathbf{2}$ & 83 & $10.0(10.3)$ & $3.18(2.99)$ & $5.56(5.78)$ & $0.68(0.59)$ \\
\hline $\mathbf{3}$ & 87 & $10.2(10.6)$ & $3.15(2.99)$ & $5.67(5.78)$ & $0.70(0.59)$ \\
\hline $\mathbf{4}$ & 85 & $10.7(10.9)$ & $3.17(2.97)$ & $5.84(5.74)$ & $0.48(0.59)$ \\
\hline
\end{tabular}

Table 2. Technological parameters of planar heterostructures.

Table 2. Technological parameters of planar heterostructures.
\begin{tabular}{|c|c|c|c|c|c|c|}
\hline$№$ & Complex & $\begin{array}{c}\text { Concentration in } \\
\text { acetone }\end{array}$ & $\begin{array}{c}\text { Velocity of } \\
\text { rotation, rpm }\end{array}$ & $\begin{array}{c}\text { PEDOT:PSS } \\
\text { thickness, nm }\end{array}$ & BDB thickness, nm & $\begin{array}{c}\text { Material of } \\
\text { cathode }\end{array}$ \\
\hline 1 & $\mathbf{1}$ & $6,59 \cdot 10^{-6} \mathrm{M}$ & 1000 & - & 45,4 & $\mathrm{Al}$ \\
\hline 2 & $\mathbf{1}$ & $8,2 \cdot 10^{-3} \mathrm{M}$ & 1000 & - & 45,4 & $\mathrm{Al}$ \\
\hline 3 & $\mathbf{1}$ & $6,59 \cdot 10^{-6} \mathrm{M}$ & 1000 & 50 & 54,8 & $\mathrm{Al}$ \\
\hline 4 & $\mathbf{1}$ & $8,2 \cdot 10^{-3} \mathrm{M}$ & 1000 & 50 & 54,8 & $\mathrm{Al}$ \\
\hline 5 & $\mathbf{1}$ & $8,2 \cdot 10^{-3} \mathrm{M}$ & 1000 & - & 47,7 & $\mathrm{Mg}$ \\
\hline 6 & $\mathbf{1}$ & $8,2 \cdot 10^{-3} \mathrm{M}$ & 1500 & - & 47,7 & $\mathrm{Mg}$ \\
\hline 7 & $\mathbf{2}$ & $7,4 \cdot 10^{-3} \mathrm{M}$ & 1000 & - & 47,3 & $\mathrm{Mg}$ \\
\hline 8 & $\mathbf{2}$ & $7,4 \cdot 10^{-3} \mathrm{M}$ & 1500 & - & 47,3 & $\mathrm{Mg}$ \\
\hline 9 & $\mathbf{3}$ & $7,7 \cdot 10^{-3} \mathrm{M}$ & 1000 & - & 47,3 & $\mathrm{Mg}$ \\
\hline 10 & $\mathbf{3}$ & $7,7 \cdot 10^{-3} \mathrm{M}$ & 1500 & - & 47,7 & $\mathrm{Mg}$ \\
\hline 11 & $\mathbf{4}$ & $8,2 \cdot 10^{-3} \mathrm{M}$ & 1000 & - & 47,7 & $\mathrm{Mg}$ \\
\hline 12 & $\mathbf{4}$ & $8,2 \cdot 10^{-3} \mathrm{M}$ & 1500 & - & & \\
\hline
\end{tabular}


and the filtrate was left above $\mathrm{CaCl}_{2}$ at room temperature. The crystals of complexes formed in 1 day were filtrated off, washed with cool isopropanol and airdried on the (yield $80-90 \%$ ). The concentration of the rare earth ions was measured by titration with a standard EDTA (ethylenediaminetetraacetic acid) aqueous solution. The results of elemental analysis for these four europium complexes are given in Table 1. Heteroligand complexes are soluble in acetone, isopropanol, toluene, chloroform, dichloromethane.

\subsection{Fabrication of the light-emitting planar heterostructures}

The EL devices with two organic layers were fabricated by using the Europium complexes 1-4 as a light emitting layer (LEML) sandwiched between a hole transport layer (HTL) and a cathode. Their different electroluminescent properties were compared. Fig. 1 shows the device configuration and the molecular structures of the compounds used in this study. The devices were fabricated on glass substrates of the size $2.5 \times 2.5 \mathrm{~mm}$ coated with a patterned ITO with the surface resistivity $8-12$ Ohm per square, which were etched to form five strips of $2 \mathrm{~mm}$ width that were used as anodes. After etching and photoresist removing, the substrates were ultrasonically cleaned in acetone and isopropanol and then dried with pressed pure dry nitrogen. After drying, the substrates were coated with HTLs. In this study, we have prepared two types of device structures. One of them (device 1) contained a BDB layer as hole-transporting one. Another structure (device 2) contained the PEDOT:PSS hole-transporting layer. The BDB (Sigma-Aldrich, Co., USA) film was formed by PVD method at the rate $0.5 \AA / \mathrm{s}$. The PEDOT:PSS film was deposited by spincoating solution of $1.3 \mathrm{wt} . \%$ dispersion in water (Sigma-Aldrich, Co., USA). The spin-coating process consisted of four stages: $250 \mu$ of PEDOT:PSS water solution were distributed on the surface of substrate and switched on rotation with velocity $600 \mathrm{rpm}$ for $10 \mathrm{~s}$, after that, rotation with velocity $2500 \mathrm{rpm}$ for $30 \mathrm{~min}$, rotation with velocity $4000 \mathrm{rpm}$ for $30 \mathrm{~min}$ and treatment at $100{ }^{\circ} \mathrm{C}$ for 1 hour. All the processes were performed in a glove box (LARGE/EXP/SP model 850NBB/EXP/SP, PlasLabs, Inc., USA) in atmosphere of pure dry nitrogen.

Films of all the complexes were deposited by spincoating method in the same glove box. Technological parameters of the structures are presented in Table 2.

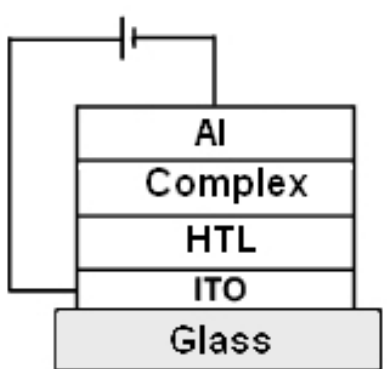

EL device

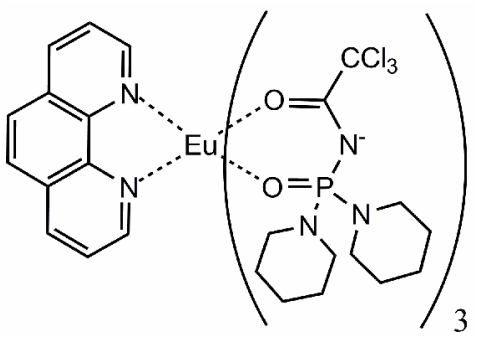

1

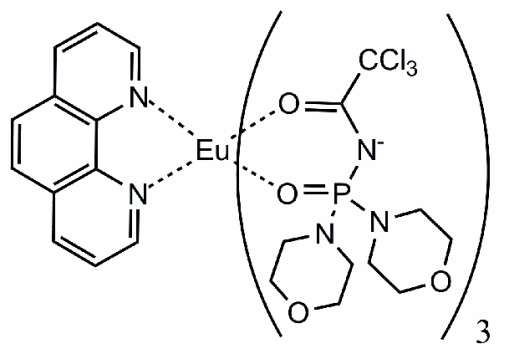

2

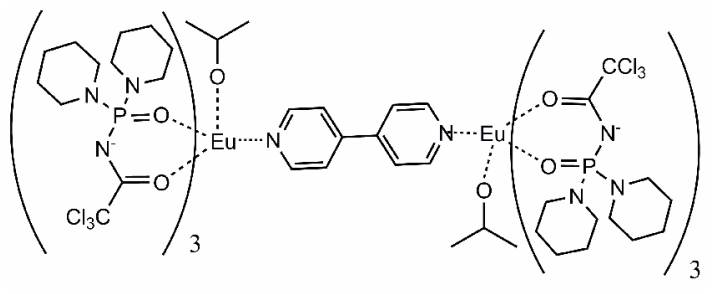

3

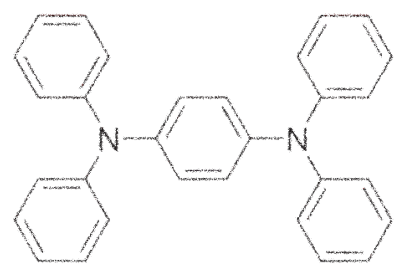

BDB

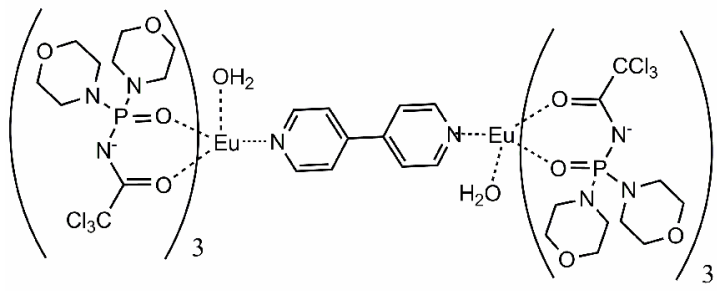

4
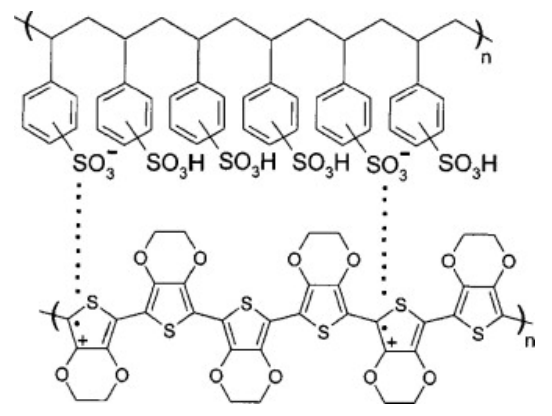

PEDOT:PSS

Fig. 1. Configuration of the EL device and molecular structures of compounds used. 
The AFM study of complex thin-film microtextures on glass substrates showed that all the films are continuous, but inhomogeneous. Micrometer size crystalline inclusions were revealed.

\subsection{Measurements}

The elemental analysis of the complexes 1-4 was carried out with an Elemental Analysensysteme GmbH EL III Universal CHNOS. The UV-VIS absorption spectra $\left(12000-30000 \mathrm{~cm}^{-1}\right)$ of the complex solutions in absolute toluene and acetone were obtained at room temperature by using a KSVU-23 "LOMO" UVspectrophotometer that was adapted for an IBM PC. The electron diffuse reflectance spectra were recorded at the same range using a SPECORD $\mathrm{M}-40$ spectrometer. The PL (excitation and emission) spectra were measured with a laser-spectral complex of excitation sources (532 nm green laser, 445 blue laser, 337 UV laser and xenon lamp DKsEl-1000 radiation), spectrophotometers and recorders. The current-voltage curves were measured using KEITHLEY 2611A Sourcemeter.

\section{Results and discussion}

For better understanding the optical properties of the complexes 1-4, comparative investigations were carried out under the same conditions.

The excitation spectra of the $10^{-3} \mathrm{M}$ toluene solutions of the complexes 1-4 by monitoring compound emission at $612 \mathrm{~nm}$ are shown in Fig. 2. It can be noted that all the spectra show the maximum peak at $334 \mathrm{~nm}$ with the shoulders at $349-358 \mathrm{~nm}$. The former peak is due to the absorption of the CAPh ligands, and the shoulders are due to the electron transitions of 1,10 phenantroline or 1,4-bipyridine. The sequence of the excitation intensity of the four complexes is as follows: $I[1]>I[4]>I[3]>I[2]$.

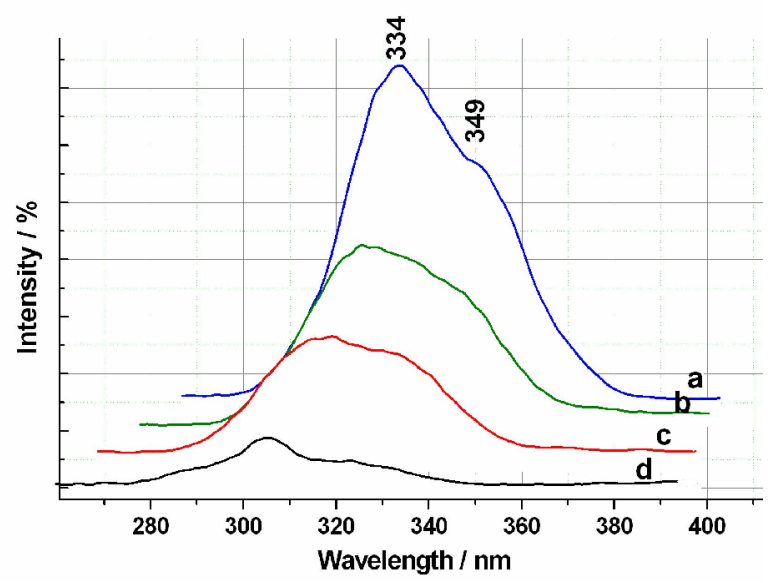

Fig. 2. Excitation spectra of the europium complexes $\left(\lambda_{\mathrm{em}} \sim 612 \mathrm{~nm}\right)$. a) $\mathrm{Eu}\left(\mathrm{L}^{1}\right)_{3}$ (phen), b) $\mathrm{Eu}_{2}\left(\mathrm{~L}^{2}\right)_{6}\left(\mathrm{H}_{2} \mathrm{O}\right)_{2}\left(\gamma \gamma^{\prime}\right.$-bipy $)$, c) $\mathrm{Eu}_{2}\left(\mathrm{~L}^{1}\right)_{6}(i \text {-prOH })_{2}\left(\gamma \gamma^{\prime}\right.$-bipy $)$, d) $\mathrm{Eu}\left(\mathrm{L}^{2}\right)_{3}$ (phen $)$.
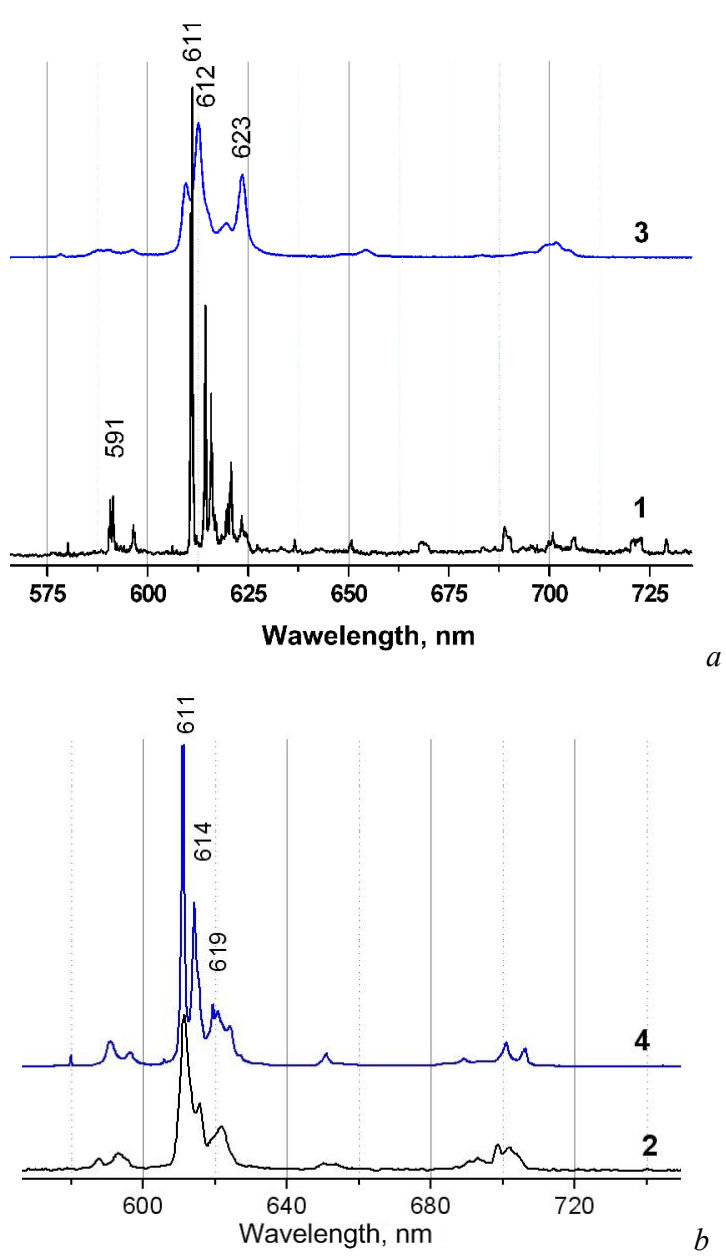

Fig. 3. Photoluminescence spectra of Complexes 1 to $4\left(\lambda_{\mathrm{ex}}=\right.$ $337.1 \mathrm{~nm}, T=77 \mathrm{~K})$.

Excitation of the ligand at $334 \mathrm{~nm}$ yields bright red emission. Fig. 3 shows emission spectra of the four complexes. All the photoluminescence spectra of the complexes 1-4 show bands corresponding to the electron transitions of $4 \mathrm{f}$ level of the $\mathrm{Eu}^{3+}$ ion: ${ }^{5} \mathrm{D}_{0}-{ }^{7} \mathrm{~F}_{0}(580 \mathrm{~nm})$, ${ }^{5} \mathrm{D}_{0}-{ }^{7} \mathrm{~F}_{1}(590 \mathrm{~nm}),{ }^{5} \mathrm{D}_{0}-{ }^{7} \mathrm{~F}_{2}$ (611 or $\left.612 \mathrm{~nm}\right),{ }^{5} \mathrm{D}_{0}-{ }^{7} \mathrm{~F}_{3}$ $(654 \mathrm{~nm})$ and ${ }^{5} \mathrm{D}_{0}-{ }^{7} \mathrm{~F}_{4}(700 \mathrm{~nm})$. Any short-wavelength emission was not observed, which confirms the absence of fluorescence of the organic ligands.

The current-voltage curves obtained using KEITHLEY 2611A Sourcemeter are represented in Figs 4 and 5.

It was found that EL starting voltages for planar heterostructures were as follows: for №1 (Table 2) $16.8 \mathrm{~V}$, №2 - $14 \mathrm{~V}$, №5 - $18 \mathrm{~V}$, №6 - $8 \mathrm{~V}$, №7 - $10 \mathrm{~V}$, №8 $-9 \mathrm{~V}$, №11 - 9.6 V, №12 - $10 \mathrm{~V}$. For planar heterostructures №3 and №4 (ITO/PEDOT:PSS/BDB/complex 1/Al with EL layers spin-coated from solutions with different velocities of rotation) as well as №9 and №10 (ITO/BDB/complex 3/Mg with EL layers spin-coated from solutions with different velocities of rotation) $\mathrm{EL}$ was not found up to the direct voltage $16 \mathrm{~V}$. 

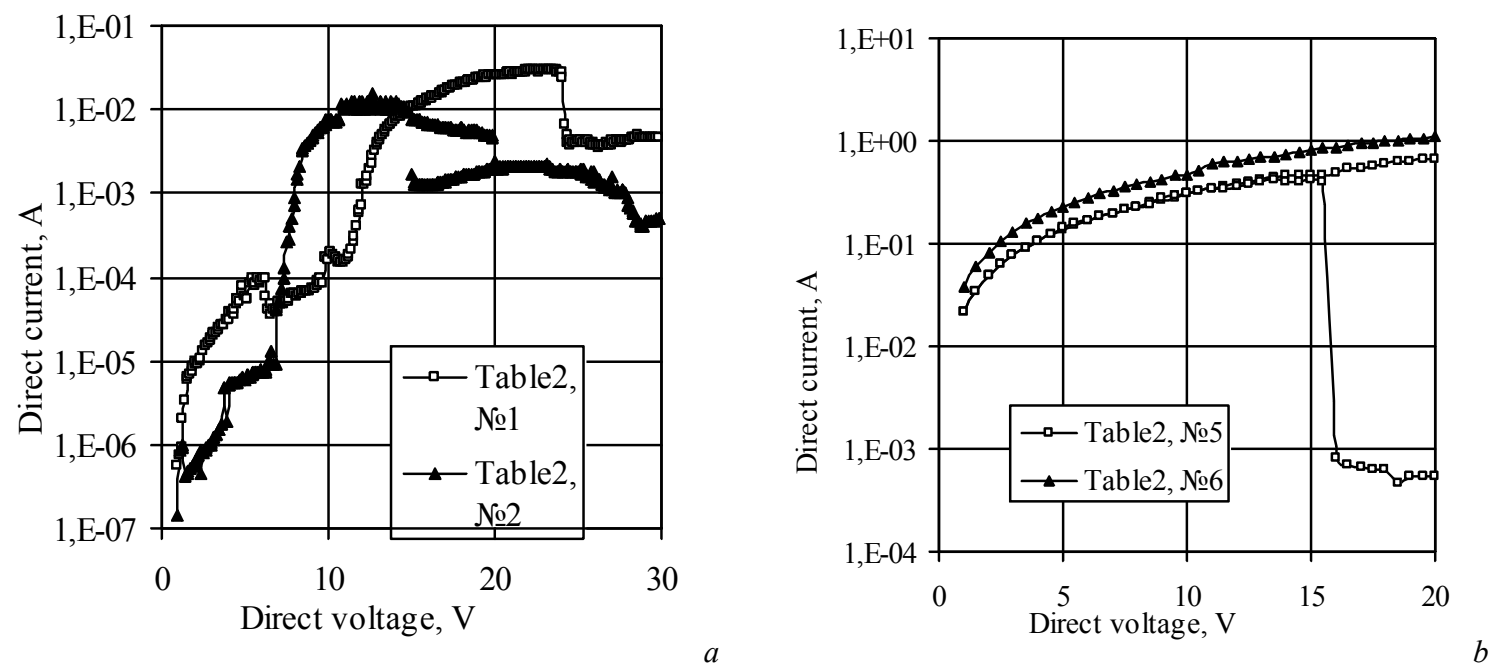

Fig. 4. Current-voltage characteristics of planar heterostructures ITO/BDB/Complex 1/Al with Complex 1 EL layers spin-coated from solution with different concentrations (a) and ITO/BDB/1/Mg with Complex 1 EL layers spin-coated from solution with different velocities of rotation (b).
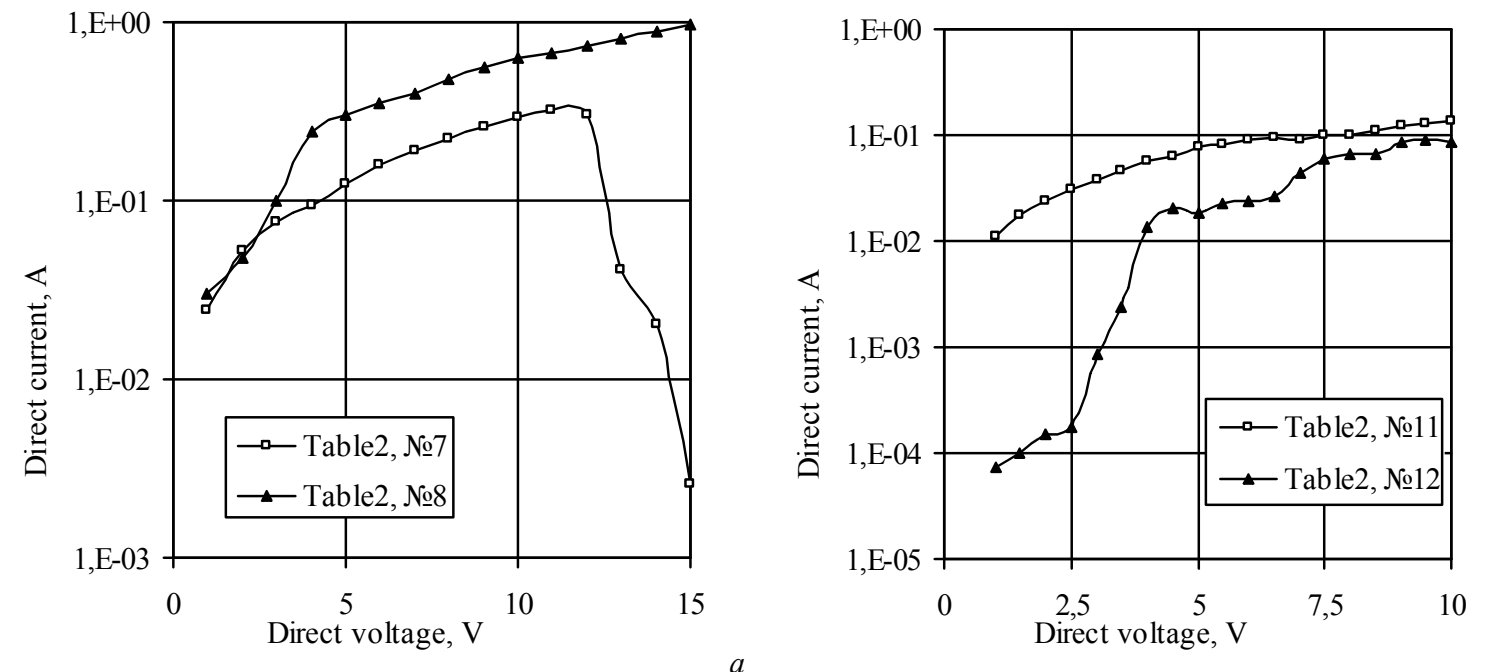

Fig. 5. Current-voltage characteristics of the planar heterostructures ITO/BDB/Complex 2 (a) or Complex 4 (b)/Mg with Complexes 2 or 3 EL layers spin-coated from solution with different velocities of rotation.

Thus, synthesis of the europium complexes with carbacylamidophosphate type ligands was performed. These europium complexes demonstrated bright narrow band of red PL, but direct using their films as EL layers was not so good. Small intensive red EL at relatively high direct voltages was observed. To use the ability of Eu complexes to emit bright red PL, the mixture of them with polymer able to excite this PL with its blue emission (due to EL) should be created and studied.

\section{References}

1. C.W. Tang and S.A. VanSlyke, Organic electroluminescent diodes // Appl. Phys. Lett. 51(12), p. 913-916 (1987).

2. J.H. Burroughes, D.D.C. Bradley, A.R. Brown, N. Marks, K. Mackay, R.H. Friend, P.L. Burns and A.B. Holmes, Light-emitting diodes based on conjugated polymers // Nature, 347, p. 539-541 (1990).

3. C. Adachi, S. Tokito, T. Tsutsui and S. Saito, Electroluminescence in organic films with threelayer structure // Jpn. J. Appl. Phys. 27(2), p. L269L271 (1988).

4. J. Kido, C. Ohtaki, K. Hongawa, K. Okugama and K. Nagai, 1,2,4-triazole derivative as an electron transport layer in organic electroluminescent devices // Jpn. J. Appl. Phys. 32(7A), p. L917-L920 (1993).

5. Y. Hamada, T. Sano, M. Fujita, T. Fujii, Y. Nishioma and K. Shibato, Organic electroluminescent devices with 8-hydroxyquinoline derivative-metal complexes as an emitter // Jpn. J. Appl. Phys. 32(4A), p. L514-L515 (1993).

6. M. Robinson, J. Ostrowski, G. Bazan, Reduced operating voltages in polymer light-emitting diodes 
doped with rare-earth complexes // Adv. Mater. 15(18), p. 1547-1551 (2003).

7. A. Dias, Lanthanide-based emitting materials in light-emitting diodes // Dalton Trans. 22, p. 2229 2241 (2007).

8. J. Kido // Trends Polym. Sci. 10, p. 350-354 (1994).

9. A.J. Epstein, Y.Z. Wang, S.W. Jessen, J.W. Blatchford, D.D. Gebler, L.B. Lin, T.L. Gustafson, T.M. Swager and A.G. MacDiarmid // Polym. Prep. 37, p. 133-137 (1996).

10. Y.Z. Wang, D.D. Gebler, D.K. Fu, T.M. Swager and A.J. Epstein, Color variable bipolar/ac lightemitting devices based on conjugated polymers // Appl. Phys. Lett. 70(24), p. 3215-3218 (1997).

11. Y.Z. Wang, R.G. Sun, F. Meghdadi, G. Leising, T.M. Swager and A.J. Epstein, Color variable multilayer light emitting devices based on conjugated polymers and oligomers // Synth. Met. 102(1-3), p. 889-892 (1999).

12. R. Reisfeld and C.K. Jorgensen, Lasers and Excited States of Rare Earths. North Holland, New York, 1978.

13. Y.X. Zheng, C.Y. Shi, Y.J. Liang, Q. Lin, C. Guo and H.J. Zhang, Synthesis and electroluminescent properties of a novel terbium complex // Synth. Met. 114(3), p. 321-323 (2000).

14. D.G. Ma, D.K. Wang, B. Li, Z.Y. Hong, S. Lu, L.X. Wang, N. Minami, N. Takada, Y. Ichino, K. Yase, H.J. Zhang, X.B. Jing and F.S. Wang, Bright green organic electroluminescent devices based on a novel thermally stable terbium complex // Synth. Met. 102(1-3), p. 1136-1137 (1999).
15. K. Okada, Y.F. Wang, T.M. Chen, M. Kitamura, T. Nakaya and H. Inoue, Bright red light-emitting organic electroluminescent devices based on a novel thiophene-containing europium complex as an emitting layer // J. Mater. Chem., 9(12), p. 3023-3026 (1999).

16. G. Yu, Y. Q. Liu, X. Wu, D.B. Zhu, H.Y. Li, L.P. Jin and M.Z. Wang, Soluble europium complexes for light-emitting diodes // Chem. Mater. 12(9), p. 2537-2541 (2000).

17. J. Kido, K. Nagai and Y. Ohashi, Electroluminescence in a terbium complex // Chem. Lett. 220, p. 657-660 (1990).

18. W.L. Li, J.Q. Yu, G. Sun, Z.R. Hong, Y. Yu, Y. Zhao, J.B. Peng and T. Tsutsui, Organic electroluminescent devices using terbium chelates as the emitting layers // Synth. Met. 91, p. 263-265 (1997).

19. V.M. Amirkhanov, V.A. Ovchynnikov, T.P. Timoshenko, Carbacylamidophosphates: Synthesis, properties, and structure of dimorfolidoN-trichloroacetylphosphorylamide // Z. Naturforsh. 53b(4), p. 481-484 (1998).

20. K. Gholivand, A.M. Alizadehgan, F. Mojahed, Crystal structures and mass spectral fragmentation studies of some new carbacylamidophosphate compounds // Polyhedron. 27(6), p. 1639-1649 (2008).

21. J. Kido, W. Ineda, M. Kimura and K. Nagai, White-light-emitting organic electroluminescent device using lanthanide complexes // Jpn. J. Appl. Phys. 35(3B), p. L394-L396 (1996). 